\title{
Bacillus Calmette-Guérin vaccination, thymic size, and thymic output in healthy newborns
}

\author{
Nina Marie Birk1', Thomas Nørrelykke Nissen', Vera Zingmark1', Jesper Kjærgaard², Lisbeth Marianne Thøstesen³, \\ Poul-Erik Kofoed ${ }^{3}$, Lone Graff Stensballe ${ }^{2}$, Andreas Andersen ${ }^{4}$, Susanne Dam Nielsen ${ }^{5}$, Christine Stabell Benn ${ }^{4}$, Ole Pryds ${ }^{1}$ \\ and Dorthe Lisbeth Jeppesen'
}

BACKGROUND: The Bacillus Calmette-Guérin vaccine (BCG) has been associated with beneficial nonspecific effects on infant health. We aimed to examine the effect of BCG at birth on thymic size and the associations between thymic output, circulating lymphocytes, risk of infection, and thymic size.

METHODS: In infants randomized to BCG or no BCG, thymic index (TI), and thymic/weight index (TWI) were measured by ultrasound at birth and at the age of 3 mo. T cell subpopulations including $\mathrm{CD}^{+} \mathrm{T}$ cells, $\mathrm{CD} 8^{+} \mathrm{T}$ cells, and recent thymic emigrants (RTEs) were assessed by flow cytometry. Infections up to age 3 mo were parent-reported.

RESULTS: BCG vaccination did not affect thymic size at age 3 mo, measured as TI. At birth, the number of lymphocytes, CD4+ T cells, CD8+ T cells, and RTEs were positively associated with $\mathrm{TI}$ and TWI. Furthermore, a reduced risk of infections up to age 3 mo was associated with a large thymic size at birth.

CONCLUSION: We found no effect of BCG vaccination on thymic size. The positive association between thymic output, lymphocytes, reduced risk of infections, and TI/TWI suggests that assessment of TI/TWI by ultrasound may be a predictor of the immunological capacity in the newborn.

B oth observational studies and recent randomized trials indicate that Bacillus Calmette-Guérin vaccination (BCG) is associated with beneficial nonspecific effects (NSEs) (1-6), reducing mortality from infections other than tuberculosis. The immunological mechanisms underlying NSEs are not clear (7). Recent studies by Kleinnijenhuis et al. suggest that "trained immunity" mediated via functional reprogramming of the monocytes may play an important role (8). Effects on the adaptive immune system are also a possibility $(9,10)$.

The thymus is essential in the generation and maturation of $\mathrm{T}$ cells and therefore, also in generating a normally functioning immune system (11). The size of the thymus has been shown to be important for infant survival in low-income countries. In Guinea-Bissau thymic size at birth, measured as thymic index
(TI), was found to have a stronger association with survival than body weight (12), and among 6-mo-old children, a doubling of the thymic size was associated with a $72 \%$ reduction in mortality up to $3 \mathrm{y}$ of age (13).

Based on the facts that both BCG vaccination and a large thymus have been associated with increased infant survival, we hypothesized that the BCG-induced beneficial nonspecific effects were mediated by increasing thymic size.

Within The Danish Calmette Study, a randomized clinical trial testing the effect of receiving BCG vs. no BCG at birth on health outcomes (14), we tested the hypothesis that BCG vaccination at birth results in increased thymic size, absolutely and relatively, by 3 mo of age. Furthermore, we evaluated the association between thymic output and thymic size, and the association between episodes of infections in the first 3 mo of life and thymic size at birth.

\section{METHODS \\ Overall Setting and Study Design}

This study was nested within The Danish Calmette Study, which was conducted between October 2012 and January 2015, and has been described in detail elsewhere (14). In brief, The Danish Calmette Study is a randomized clinical multicenter trial with 1:1 allocation of 4,262 infants to either BCG vaccination or no BCG vaccination within $7 \mathrm{~d}$ of birth. The inclusion criteria were gestational age $\geq 32 \mathrm{wk}$ and a birth weight $\geq 1,000 \mathrm{~g}$. Exclusion criteria were maternal intake of immune modulating medicine during pregnancy, severe illness, or major malformations. The intervention group was vaccinated intradermally with BCG vaccine (SSI strain 1331), in the standard dose of $0.05 \mathrm{ml}$ in the upper, lateral part of the left shoulder. Background information on demographics and risk factors were collected by a structured telephone interview conducted in the third trimester of pregnancy.

\section{Study Population}

From March to November 2013, all children born at Copenhagen University Hospital, Hvidovre were invited to participate in this substudy including a thymus scan at randomization and at 3 mo follow up. By coincidence, none of the children were preterm children, hence our study population consisted of term (born between gestational weeks $37+0$ to $41+6$ ) children only. A subgroup of these infants were further included into a substudy on T and B cells (N.M. Birk et al. The effect

\footnotetext{
'Department of Pediatrics, Copenhagen University Hospital, Hvidovre, Denmark; ${ }^{2}$ The Department of Pediatrics and Adolescent Medicine, Juliane Marie Centret, Rigshospitalet, Copenhagen University Hospital, Denmark; ${ }^{3}$ Department of Pediatrics, Kolding Hospital, Denmark; ${ }^{4}$ Research Center for Vitamins and Vaccines (CVIVA), Statens Serum Institut, Copenhagen, Denmark; ${ }^{5}$ Department of infectious diseases, Rigshospitalet, Copenhagen University Hospital, Denmark. Correspondence: Nina Marie Birk (ninabirk@dadlnet.dk)

Received 10 August 2016; accepted 30 November 2016; advance online publication 5 April 2017. doi:10.1038/pr.2017.27
} 
of neonatal Bacillus Calmette-Guérin vaccination on $\mathrm{T}$ and $\mathrm{B}$ lymphocyte subsets: a clinical randomized trial (unpublished data) and had blood samples collected for flow cytometry analyses (Figure 1).

\section{Baseline Measurements}

Immediately following randomization the children had their thymic size measured by ultrasound. This was again immediately followed by vaccination of the BCG group. The blood sample used for measuring $\mathrm{T}$ and $\mathrm{B}$ cells cell subsets by flow cytometry was collected $4 \mathrm{~d}( \pm 2 \mathrm{~d})$ after the randomization, ultrasound examination, and vaccination.

\section{Follow-up}

At 3 mo of age, before having received any standard childhood vaccines, all infants were invited for a clinical examination at the hospital preceded by a follow-up telephone interview including questions about number of illness episodes in the first 3 mo of life. Questions on episodes of illness were designed to target illness due to infections (15) and parents were encouraged to take notes of their child's illness in a diary supplied by study staff at the time of randomization. As part of the clinical examination, thymic size was assessed again. Following the clinical examination, another blood sample was obtained (Figure 1).

\section{Ultrasound Examination of the Thymus}

By transsternal ultrasound, thymic size was estimated as thymic index (TI) and thymic weight index (TWI), an absolute and relative volume estimate, respectively. First, the thymus gland was identified in a horizontal scanning plane and the largest transverse diameter of the thymus was obtained (Figure 2a). Second, in a sagittal scanning plane, the area of the largest lobe was assessed (Figure 2b). Both measurements were obtained twice, and in case of more than $15 \%$ difference, both measurements were repeated. The means of each of the two measurements were multiplied and the value was defined as the thymic index $\left(\mathrm{cm}^{3}\right)$ (16). For the weight-adjusted index TWI, TI was divided by weight of the child in kilograms $\left(\mathrm{cm}^{3} / \mathrm{kg}\right)$. All measurements were conducted with a Sonosite MicroMaxx transportable ultrasound scanner with an $8-5 \mathrm{MHz}$ C11e transducer, manufactured by SonoSite, Bothell, WA.

As thymus scans were performed by two investigators and interobserver variation has been reported (12), the potential interobserver variation in this study was assessed; we found no significant difference between observers (Supplementary Methods S1 online).

\section{T Cell Subsets, Flow Cytometry, and Lymphocytes}

For the measurement of lymphocytes, blood was collected in K2EDTA (ethylenediaminetetraacetic acid) tubes (Greiner BioOne, Kremsmünster, Austria). Differential white blood cell count was measured by standard technique using a Sysmex XE-5000 at the Department of Clinical Biochemistry, Copenhagen University Hospital, Hvidovre, Denmark.

$\mathrm{CD} 4^{+} \mathrm{T}$ cells, $\mathrm{CD}^{+}{ }^{+} \mathrm{T}$ cells, $\mathrm{CD} 4^{+} \mathrm{RTE}\left(\mathrm{CD} 4^{+} \mathrm{CD} 45 \mathrm{RA}^{+} \mathrm{CD} 31^{+}\right)$, and $\mathrm{CD}^{+} \mathrm{RTEs}\left(\mathrm{CD} 8^{+} \mathrm{CD} 45 \mathrm{RA}^{+} \mathrm{CD} 31^{+}\right)$were measured in peripheral blood using a 6-color FACS Canto (Becton Dickinson (BD), Franklin Lakes, NJ) and data were processed using FACS Diva software (BD). In brief, $100 \mu$ l of EDTA blood was incubated with fluorescent dye-conjugated monoclonal antibodies at room temperature for 20 min according to the manufacturer's instructions. Erythrocytes were then lysed with $2 \mathrm{ml}$ of Lysing Solution (BD) at room temperature for $20 \mathrm{~min}$, and samples were washed and resuspended in FACS Flow (BD). Monoclonal antibodies used were isotype control IgG1 peridinin chlorophyll proteins-cyanine (PerCP-Cy5.5), IgG1 fluorescein isothiocyanate (FITC), IgG2b allophycocyanin (APC), and IgG1 allophycocyanin combined with an analog of $\mathrm{Cy} 7$ (APC-H7) further CD8-PerCPCy5.5, CD31-FITCH, CD45RA-APC, and CD4-APC-H7 all purchased from $\mathrm{BD}$.

\section{Power Calculation}

A post hoc power calculation was conducted based on previous work with thymic index, where mean TI in infants at 4 mo of age was $3.0 \mathrm{~cm}^{3}$ (SD 1.5). To detect a difference of $20 \%$ in the intervention group, we needed to include 132 in each group; thus the number of included infants (156 in the intervention group and 158 in the control group) provided suitable power ( $\alpha: 0.05, \beta 0.9$, two-sided test).

\section{Statistical Methods}

To obtain normal distribution, TI and TWI were log-transformed. The primary estimate of the BCG-effect on TI was the geometric mean ratio (GMR) with 95\% confidence interval (CI) obtained as the anti-logged coefficient from a linear regression with log-TI as outcome and randomization group and baseline log-TI as covariates. The primary estimate of the BCG-effect on TWI was obtained similarly. The interpretation of a TI GMR of eg.1.15 being that children randomized to BCG vaccination had a $15 \%$ larger TI than their controls.

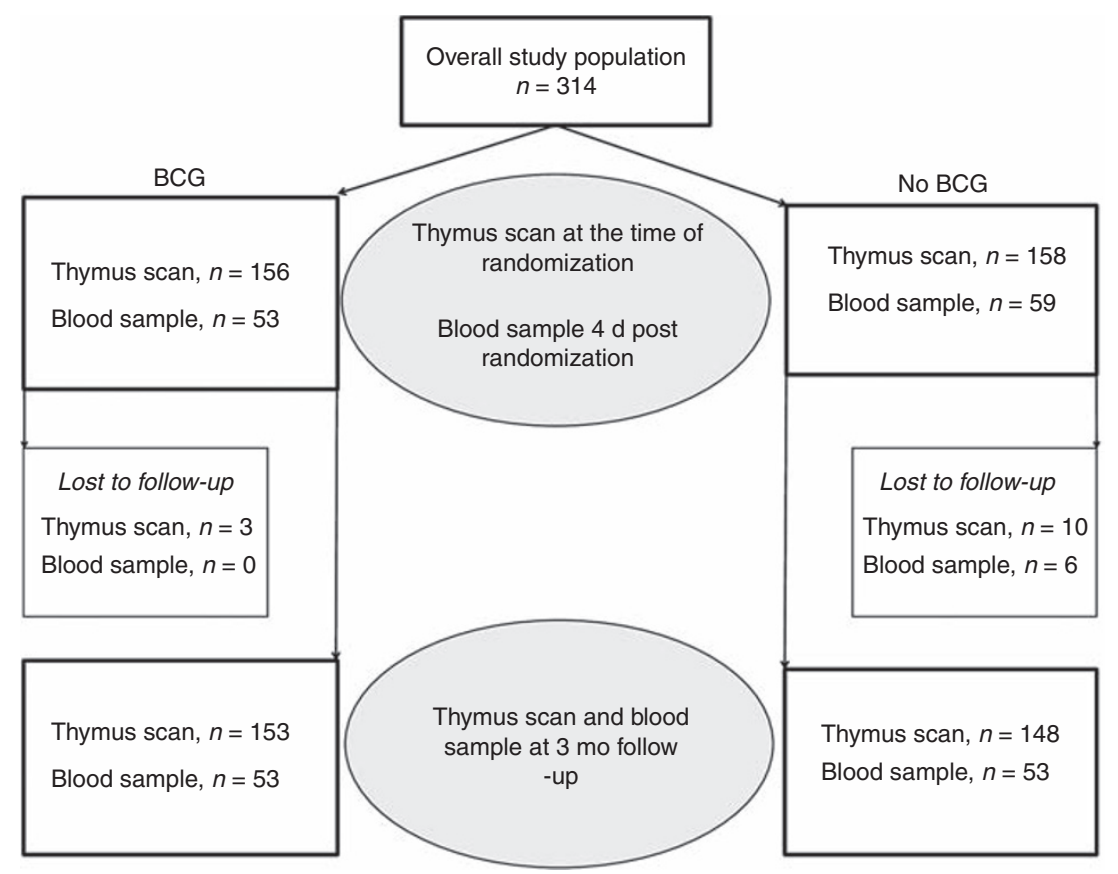

Figure 1. Flowchart of infants randomized to BCG or no BCG at birth in the study on BCG and thymic size and the association between T cells, infections, and thymic size. 


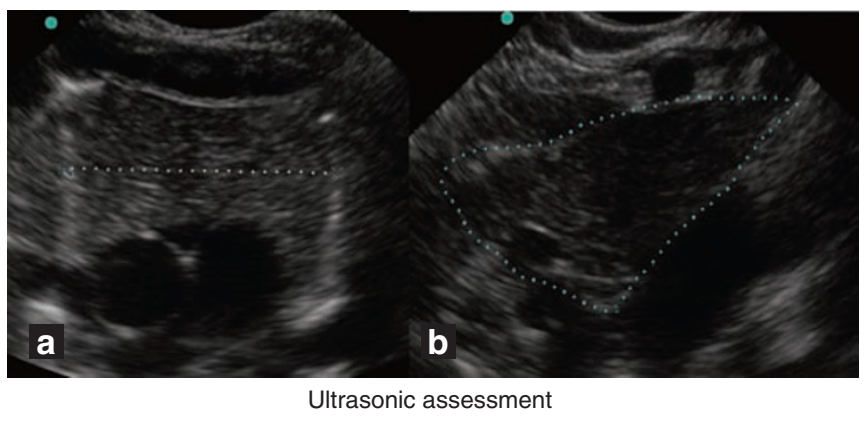

Figure 2. Sonograms. Ultrasonic assessment of thymic size. An immunological evaluation within The Danish Calmette Study randomizing infants to BCG or no BCG at birth. (a) In a horizontal scanning plane the thymus is seen as an echo-poor structure surrounded by its echo-rich capsule surrounding the big vessels (Pulmonary artery and Ascending aorta).The largest transverse diameter of the thymus is measured (dashed line). (b) In a sagittal scanning plane, the area of the largest lobe is assessed (dashed line).

We had few missing values of both outcome variables and covariates, and complete case analyses were done; i.e., we included only children for whom all information was available.

On the basis of previous findings of BCG having more pronounced beneficial nonspecific effects in girls (17), both overall and sex-stratified primary outcome estimates were calculated. Furthermore, we had prespecified that we would investigate potential effect modification by gestational age, birth weight, cesarean section, antibiotics given to the mother during labor, maternal BCG, ethnicity of the parents, atopic predisposition, siblings, and age at randomization (day $0-1$ vs. $2-7$ ).

The analysis of the association between $\mathrm{T}$ cells, lymphocytes, and TI/TWI was done using linear regression analysis with absolute cell count and lymphocytes as outcomes, and $\log 2-\mathrm{TI} / \log 2-\mathrm{TWI}$ as covariates. Cell measurements were done $4 \mathrm{~d}$ postrandomization, so we adjusted for BCG/no BCG.

The analysis of the association between episodes of illness and TI/ TWI was assessed in Poisson regression test for trend using a categorical variable of none or at least one episode of parent-reported illness during the first 3 mo as outcome and TI/TWI as quartiles and sex as covariates. These analyses were adjusted for BCG/no BCG.

All analyses were performed using STATA 13.1 (StataCorp LP, College Station, TX).

\section{Ethical Considerations}

This study was approved by the Committees on Biomedical Research Ethics (J.no. H-3-2010-087), the Danish Data Protection Board (J.no. 2009-41-4141), and the Danish Medicines Agency (J.no. 2612-4356. EudraCT 2010-021979-85. Protocol 2009-323).

The study was registered at http://www.clinicaltrials.gov with registration number NCT01694108. The trial was supervised by the Good Clinical Practice Units of the Capital Region, Denmark and monitored by an independent Data Safety Monitoring board.

The ultrasound examination did not cause any discomfort in the infants and is not known to be associated with any adverse events (18). Infants were included after both oral and written information was provided and a signed consent form from both parents was obtained. The study was conducted according to The Declaration of Helsinki.

\section{RESULTS}

A total of 314 healthy term infants were included in the study and had an ultrasound examination of the thymus at birth, 156 were randomized to BCG and 158 to no BCG.

The two groups had similar baseline characteristics although infants in the BCG group were on average $0.11 \mathrm{~kg}$ heavier at birth $(P=0.04)$ (Table 1$)$. At baseline, the two groups had
Table 1. Background characteristics at baseline and at follow-up 3 mo later in infants randomized to BCG or no BCG at birth

\begin{tabular}{|c|c|c|c|}
\hline & BCG & No BCG & \\
\hline Baseline & $n=156$ & $n=158$ & $P$ value \\
\hline Age at randomization (days) ${ }^{\mathrm{a}}$ & $1(1-6)$ & $1(1-5)$ & 0.35 \\
\hline Sex $(\text { male })^{b}$ & $86(55 \%)$ & $86(54 \%)$ & 0.9 \\
\hline Gestational age (weeks) ${ }^{a}$ & $40(38-41)$ & $40(38-41)$ & 0.51 \\
\hline Weight $(\mathrm{kg})^{\mathrm{a}}$ & $3.5(3.0-4.2)$ & $3.5(2.8-4.1)$ & 0.04 \\
\hline Cesarean section $^{\mathrm{b}}$ & $29(19 \%)$ & $43(27 \%)$ & 0.07 \\
\hline Maternal BCG ${ }^{b}$ & $33(21 \%)(1)$ & $30(19 \%)$ & 0.67 \\
\hline $\begin{array}{l}\text { At least one parent of non-Danish } \\
\text { ethnicity }{ }^{b}\end{array}$ & $21(13 \%)$ & $30(19 \%)$ & 0.24 \\
\hline $\begin{array}{l}\text { Maternal smoking during } \\
\text { pregnancy }^{\mathrm{b}}\end{array}$ & $12(8 \%)$ & $11(7 \%)$ & 0.82 \\
\hline Level of maternal education ${ }^{b}$ & (1) & (1) & 0.77 \\
\hline $\begin{array}{l}\text { Basic schooling and } \\
\text { nontheoretical education }\end{array}$ & $30(19 \%)$ & $34(22 \%)$ & \\
\hline $\begin{array}{l}\text { Theoretical education incl BA } \\
\text { level }\end{array}$ & $69(45 \%)$ & $72(46 \%)$ & \\
\hline Master level or more & $56(36 \%)$ & $51(32 \%)$ & \\
\hline Siblings ${ }^{b}$ & $62(40 \%)$ & $55(35 \%)$ & 0.37 \\
\hline Atopic predisposition ${ }^{c}$ & $103(66 \%)$ & $88(56 \%)$ & 0.06 \\
\hline Follow-up at 3 mo & $n=153(3)$ & $N=148(10)$ & \\
\hline $\begin{array}{l}\text { Age at clinical examination } \\
\text { (days) })^{\mathrm{a}}\end{array}$ & $90(83-100)$ & $89(82-102)$ & 0.51 \\
\hline Weight $(\mathrm{kg})^{\mathrm{a}}$ & $6.1(5.2-7.2)$ & $6.1(5.2-7.2)$ & 0.55 \\
\hline Exclusively breastfeed at $3 \mathrm{mo}^{\mathrm{b}}$ & $95(62 \%)$ & $84(57 \%)$ & 0.35 \\
\hline $\begin{array}{l}\text { Number of parent reported } \\
\text { infections } \geq 1^{\mathrm{b}}\end{array}$ & $9(6 \%)$ & $16(10 \%)$ & 0.15 \\
\hline $\begin{array}{l}\text { Number of visits to the general } \\
\text { practitioner } \geq 1^{\mathrm{b}}\end{array}$ & $49(32 \%)$ & $62(42 \%)$ & 0.08 \\
\hline Lost to follow-up ${ }^{b}$ & $3(2 \%)$ & $10(6 \%)$ & 0.09 \\
\hline
\end{tabular}

similar thymic size, the GMR in the BCG vs. the control group being $1.02(0.95-1.09)$ for TI and $0.99(0.93-1.05)$ for TWI (Table 2).

Parents of $1 \%$ of the infants (3/314) withdrew consent to participate and $3 \%(10 / 314)$ were lost to follow-up. There was no significant difference in the proportion of dropouts between groups (BCG $2 \%(n=3)$ vs. no BCG 6\% $(n=10), P=0.09)$ (Table 1).

The remaining 301 infants were scanned at 3 mo followup $($ mean age $=90 \mathrm{~d}$ ). There were no significant differences between groups with regard to age, weight, breastfeeding, parent-reported illness at follow-up, or general practitioner consultations (GP) (Table 1).

The GM of TI was 12.8 vs. $12.6\left(\mathrm{~cm}^{3}\right)$ in the BCG group vs. the control group at birth, and 33.0 vs. $34.2\left(\mathrm{~cm}^{3}\right)$ at followup. For TWI, it was 3.6 vs. $3.7\left(\mathrm{~cm}^{3} / \mathrm{kg}\right)$ at birth, and $5.4 \mathrm{~cm}^{3}$ vs. $5.6\left(\mathrm{~cm}^{3} / \mathrm{kg}\right)$ at follow-up, respectively (Table 2$)$. Useful 
Table 2. Overall and sex-specific effects of BCG vs. no BCG on thymic index (TI) and thymic weight index (TWI)

\begin{tabular}{|c|c|c|c|c|}
\hline & \multicolumn{2}{|c|}{ Mean a thymic size } & \multirow{2}{*}{$\begin{array}{l}\text { GMR }(95 \% \mathrm{Cl})^{\mathrm{b}} \\
\text { BCG vs. no BCG }\end{array}$} & \multirow[b]{2}{*}{$\begin{array}{c}P \\
\text { value }\end{array}$} \\
\hline & $\begin{array}{c}\text { BCG } \\
(n=153)\end{array}$ & $\begin{array}{l}\text { No BCG } \\
(n=148)\end{array}$ & & \\
\hline $\begin{array}{l}\text { Area of the largest lobe } \\
\left(\mathrm{cm}^{2}\right) \text {, at birth }\end{array}$ & 4.0 & 4.0 & - & \\
\hline $\begin{array}{l}\text { Area of the largest lobe } \\
\left(\mathrm{cm}^{2}\right) \text {, at follow-up }\end{array}$ & 7.7 & 7.9 & - & \\
\hline $\begin{array}{l}\text { Largest transverse } \\
\text { diameter }(\mathrm{cm}) \text {, at birth }\end{array}$ & 3.2 & 3.1 & - & \\
\hline $\begin{array}{l}\text { Largest transverse } \\
\text { diameter }(\mathrm{cm}) \text {, at follow-up }\end{array}$ & 4.3 & 4.3 & - & \\
\hline \multicolumn{5}{|l|}{$\mathrm{TI}\left(\mathrm{cm}^{3}\right)$ at birth } \\
\hline Overall & 12.8 & 12.6 & $1.02(0.95-1.09)$ & 0.61 \\
\hline Males & 12.9 & 12.8 & $1.01(0.92-1.10)$ & $0.71^{c}$ \\
\hline Females & 12.7 & 12.3 & $1.03(0.93-1.14)$ & \\
\hline \multicolumn{5}{|l|}{$\mathrm{TI}\left(\mathrm{cm}^{3}\right)$ at follow-up } \\
\hline Overall & 33.0 & 34.2 & $0.96(0.89-1.02)$ & 0.19 \\
\hline Males & 34.0 & 36.9 & $0.92(0.84-1.01)$ & 0.30 \\
\hline Females & 31.8 & 31.6 & $0.98(0.90-1.09)$ & \\
\hline \multicolumn{5}{|l|}{ TWI $\left(\mathrm{cm}^{3} / \mathrm{kg}\right)$ at birth } \\
\hline Overall & 3.6 & 3.7 & $0.99(0.93-1.05)$ & 0.66 \\
\hline Males & 3.6 & 3.7 & $0.97(0.90-1.05)$ & 0.57 \\
\hline Females & 3.6 & 3.6 & $1.01(0.92-1.10)$ & \\
\hline \multicolumn{5}{|l|}{ TWI (cm3/kg) at follow-up } \\
\hline Overall & 5.4 & 5.6 & $0.96(0.90-1.02)$ & 0.23 \\
\hline Males & 5.3 & 5.8 & $0.94(0.85-1.02)$ & 0.35 \\
\hline Females & 5.4 & 5.4 & $0.99(0.91-1.09)$ & \\
\hline
\end{tabular}

aGeometric mean. bGeometric mean ratio with $95 \%$ confidence interval. Follow-up estimates are adjusted for baseline, TI/TWI, and sex. Test of interaction between BCG and sex.

measurements were obtained for all children at baseline and at follow-up.

\section{Effect of BCG on TI/TW}

No difference in thymic size at follow-up was found when comparing the BCG and the control group with regard to TI, the GMR being 0.96 (0.89-1.02), and TWI (GMR: 0.96 (0.90-1.02)) (Table 2). Adjusting for weight at baseline did not change the estimates (data not shown).

\section{Potential Effect Modification}

No effect modification by sex on the effect of BCG on TI at follow-up was found. The GMR was $0.92(0.84-1.01)$ in males and 0.98 (0.90-1.09) in females, $P=0.30$ for interaction (Table 2). The same was seen for TWI (Table 2).

For children with no siblings, BCG was associated with a smaller TI (GMR: $0.92(0.84-0.99)), P$ value for interaction = 0.07 , and a smaller TWI (GMR: $0.91(0.85-0.99)$ ) at 3 mo of age, $P$ value for interaction $=0.05$ (Table 3$)$. None of the other pre-specified effect modifiers influenced the effect of BCG (Table 3).

\section{Association Between T Lymphocyte Cell Subsets, Lymphocytes, and $\mathrm{TI} / \mathrm{TWI}$}

At birth, we found a positive association between $\mathrm{CD}^{+} \mathrm{T}$ cells, $\mathrm{CD}^{+} \mathrm{T}$ cells, $\mathrm{CD} 4^{+}$recent thymic emigrants (RTEs), $\mathrm{CD}^{+}$RTEs, lymphocytes $(n=112)$, and TI (Figure 3$)$. The positive association was stronger when looking at $\mathrm{CD} 4^{+} \mathrm{T}$ cells and TWI (Regression coefficient (a): 973 cells/ $\mu$ l per doubling of TWI, 95\% CI 561-1,386, $P<0.001$ ), $\mathrm{CD}^{+} \mathrm{T}$ cells (a: 146 cells $/ \mu \mathrm{l}$ pr. doubling of TWI, 95\% CI $4-287, P=0.044), \mathrm{CD}^{+}$ RTEs (a: 595 cells/ $\mu$ pr. doubling of TWI, 95\% CI 323-867, $P$ $<0.001$ ), CD8 ${ }^{+}$RTEs (a: 154 cells/ $\mu$ pr. doubling of TWI, 95\% CI 16-292, $P=0.028$ ), and lymphocytes (a: 1,498 cells/ $\mu$ l pr. doubling of TWI, 95\% CI 924-2,072, $P<0.001$ ). The interpretation being that a doubling of TWI increases circulating lymphocytes by 1,498 cells/ $\mu$ l. At 3 mo of age, there were no associations between cell subsets $(n=106)$ and TI/TWI (data not shown).

\section{Association Between Episodes of Infectious Diseases and TI/TWI} When looking at the association between infections assessed as none or at least one episode of infections during the first 3 mo of life and thymic size at birth in quartiles, a test for trend showed that with each step up in quartile, the incidence of infections decreased by $25 \%$ (RR: $0.75,95 \%$ CI $0.55-1.05, P=0.09$ for TI); and 27\% (RR: $0.73,95 \%$ CI $0.54-0.99, P=0.04$ ) for TWI. Compared with children in the three lower quartiles of TI, the children in the highest quartile had a $58 \%$ (IRR 0.42, 95\% CI $0.13-1.35, P=0.20$ ) decrease in risk of infections; for TWI it was $75 \%$ (IRR 0.25 , 95\% CI 0.06-1.03, $P=0.05$ ) (Figure 4). We found no association between number of general practitioner consultations and TI/TWI (data not shown).

\section{DISCUSSION}

BCG vaccination at birth did not affect thymic size, assessed by ultrasound as TI and TWI at birth and in 3-mo-old infants. Thymic size at birth was associated with increasing numbers of circulating lymphocytes and $\mathrm{T}$ cell subsets recently generated in the thymus as well as with reduced risk of parent-reported infections.

Strengths of this study were the randomized design, the low drop-out rate $(4 \%)$, and that examiners were blinded. This study was not designed to assess the associations between $\mathrm{T}$ cells, infections, and TI/TWI. However, the analyses represent an internal quality control in this study and the associations are in line with previous findings. The overall number of infections in the first 3 mo of life is low and numbers were parent reported, representing a potential weakness in the assessment of the association between infections and thymic size.

To our knowledge, this is the first randomized trial testing the effect of BCG on thymic size in newborns in a high income country. In West Africa Eriksen et al. tested the effect of providing BCG at birth to low-birth-weight infants compared 
Table 3. The effect of BCG at birth on thymic index/thymic weight index measured at 3 mo of age, stratified by baseline covariates

\begin{tabular}{|c|c|c|c|c|c|c|c|c|c|c|c|}
\hline \multirow{3}{*}{ Effect modifiers } & \multirow[b]{3}{*}{$n$} & \multicolumn{5}{|c|}{ Thymic index } & \multicolumn{5}{|c|}{ Thymic weight index } \\
\hline & & BCG & No BCG & & & & \multirow{2}{*}{\multicolumn{2}{|c|}{$\begin{array}{l}\text { BCG No BCG } \\
\text { GM at birth/3 mo }\end{array}$}} & \multirow{2}{*}{$\begin{array}{l}\text { GMR } \\
1.00\end{array}$} & \multirow{2}{*}{$\begin{array}{c}95 \% \mathrm{Cl} \\
(1.00-1.00)\end{array}$} & \multirow{2}{*}{$\begin{array}{c}P \text { value } \\
0.22\end{array}$} \\
\hline & & \multicolumn{2}{|c|}{$\mathrm{GM}^{\mathrm{a}}$ at birth/3 mo } & $\begin{array}{c}\mathrm{GMR}^{\mathrm{b}} \\
1.00\end{array}$ & $\begin{array}{c}95 \% \mathrm{Cl} \\
(1.00-1.00)\end{array}$ & $P$ value $^{c}$ & & & & & \\
\hline Birthweight (kg) & 301 & & & 1.00 & $(0.99-1.00)$ & 0.25 & & & 1.00 & $(0.99-1.00)$ & 0.32 \\
\hline Cesarean section & & & & & & 0.51 & & & & & 0.54 \\
\hline $\begin{array}{l}\text { Antibiotics given to the } \\
\text { mother during labor }\end{array}$ & & & & & & 0.83 & & & & & 0.75 \\
\hline Yes & 68 & $12.53 / 34.22$ & $13.14 / 36.56$ & 0.97 & $(0.84-1.12)$ & & $3.61 / 5.55$ & $3.71 / 5.82$ & 0.98 & $(0.86-1.12)$ & \\
\hline No & 233 & $12.85 / 32.66$ & $12.40 / 33.60$ & 0.95 & $(0.88-1.03)$ & & $3.60 / 5.33$ & $3.63 / 5.59$ & 0.96 & $(0.89-1.12)$ & \\
\hline No & 279 & $12.75 / 32.83$ & $12.53 / 34.20$ & 0.95 & $(0.88-1.02)$ & & $3.59 / 5.34$ & $3.64 / 5.63$ & 0.96 & $(0.90-1.02)$ & \\
\hline Maternal BCG & & & & & & 0.61 & & & & & 0.47 \\
\hline Yes & 61 & $12.69 / 35.42$ & $12.62 / 36.20$ & 0.99 & $(0.85-1.15)$ & & $3.63 / 5.78$ & $3.72 / 5.90$ & 1.01 & $(0.87-1.16)$ & \\
\hline No & 237 & $12.78 / 32.31$ & $12.57 / 33.82$ & 0.94 & $(0.87-1.02)$ & & $3.59 / 5.27$ & $3.64 / 5.58$ & 0.95 & $(0.88-1.02)$ & \\
\hline $\begin{array}{l}\text { At least one parent of } \\
\text { non-Danish ethnicity }\end{array}$ & & & & & & 0.30 & & & & & 0.42 \\
\hline Yes & 48 & $11.53 / 31.43$ & $12.10 / 36.60$ & 0.88 & $(0.74-1.05)$ & & $3.37 / 5.13$ & $3.46 / 5.76$ & 0.91 & $(0.77-1.06)$ & \\
\hline No & 252 & $12.98 / 33.27$ & $12.67 / 33.75$ & 0.97 & $(0.90-1.05)$ & & $3.64 / 5.42$ & $3.69 / 5.61$ & 0.97 & $(0.91-1.04)$ & \\
\hline Atopic predisposition ${ }^{d}$ & & & & & & 0.18 & & & & & 0.14 \\
\hline Yes & 198 & $12.91 / 33.62$ & $12.44 / 33.23$ & 0.99 & $(0.80-1.01)$ & & $3.61 / 5.48$ & $3.51 / 5.39$ & 0.99 & $(0.92-1.08)$ & \\
\hline $0-1 d$ & 176 & $12.28 / 32.66$ & $12.15 / 34.07$ & 1.05 & $(0.96-1.15)$ & 0.91 & $3.48 / 5.32$ & $3.54 / 5.66$ & 1.05 & $(0.97-1.14)$ & 0.58 \\
\hline $2-7 d$ & 125 & $13.44 / 33.47$ & $13.20 / 34.50$ & 1.04 & $(0.94-1.16)$ & & $3.76 / 5.46$ & $3.81 / 5.61$ & 1.02 & $(0.92-1.12)$ & \\
\hline $\begin{array}{l}\text { "Geometric mean. } \\
{ }^{\mathrm{b} G e o m e t r i c ~ m e a n ~ r a t i o . ~} \\
\text { cP value for interaction betweer } \\
\text { dAtopic predisposition is define } \\
\text { rhinoconjunctivitis, or food aller }\end{array}$ & sal & $\begin{array}{l}\text { on group an } \\
\text { he first degr }\end{array}$ & $\begin{array}{l}\text { tential } \\
\text { ee with }\end{array}$ & 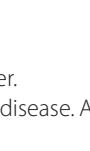 & 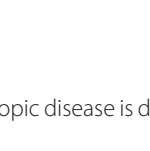 & . & 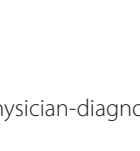 & 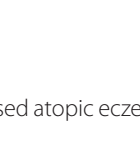 & . & allergic & \\
\hline
\end{tabular}

to the usual practice of postponing BCG until infants had reached a weight of $2.5 \mathrm{~kg}$ (Eriksen et al., "The effect of early Bacille Calmette-Guérin vaccine on thymic size in low birth weight infants in Guinea-Bissau", personal communication.). Consistent with the present study, no overall or sex differential effect on TI or TWI after $4 \mathrm{wk}$ was found. Caution in comparing the two cohorts should be taken as inclusion criteria differed and the settings were different in many aspects (19).

We observed a tendency for BCG being associated with diminished thymic growth among children with no siblings, but not among children with siblings (Table 3). This may be caused by baseline differences; the BCG group had a smaller geometric mean in the "no siblings" group compared to the "siblings" group at baseline which seemed to be sustained at 3 mo.

Thus, based on the existing studies, BCG does not exert nonspecific effects by modifying thymic size. With the introduction of the concept "Trained immunity" Kleinnijenhuis et al. challenge the paradigm that immunological memory after BCG is restricted to the adaptive immune response by showing that BCG induced an enhanced release of monocyte-derived cytokines to unrelated pathogens, mediated by epigenetic reprogramming of innate immune cells independently of $\mathrm{B}$ and $\mathrm{T}$ cells (8). If the explanation for the observed beneficial NSEs of 

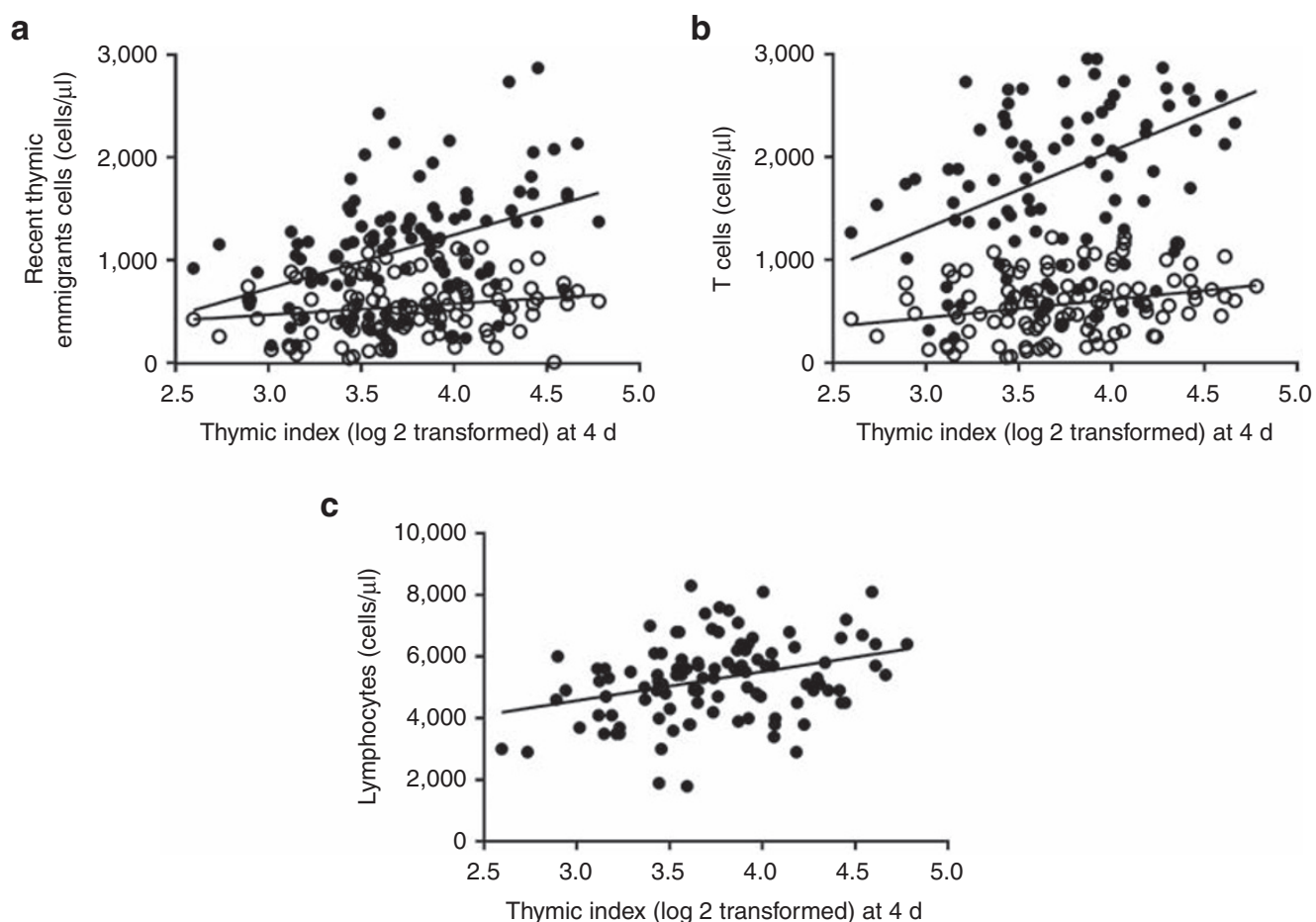

Figure 3. Plots of the association between T cell subsets, lymphocytes, and thymic index in newborns randomized to BCG or no BCG. (a) The association between the absolute cell count (cells/ $\mu$ l) of recent thymic emigrants (RTEs) and TI at $4 \mathrm{~d}$. The linear regression coefficient for CD4+ RTEs (filled circles) = 523 cells $/ \mu$ l pr. doubling of TI, $95 \% \mathrm{Cl} 281-764, P<0.001$ and for CD8+ RTEs (open circles) $=169,95 \% \mathrm{Cl} 48-290, P=0.007, n=112$. (b) The association between the absolute cell count (cells/ $\mu \mathrm{l}$ ) of CD4+ and CD8+T cells and Tl at $4 \mathrm{~d}$. The linear regression coefficient for CD4+ (filled circles) $=849$ cells $/ \mu \mathrm{l}$ pr. doubling of $\mathrm{TI}, 95 \% \mathrm{Cl} 483-1,215, P<0.001$ and for $\mathrm{CD} 8+$ (open circles) $=165,95 \% \mathrm{Cl} 41-290, P=0.01, n=112$. (c) The association between the absolute cell count (cells/ $\mu \mathrm{l}$ ) of lymphocytes and Tl at $4 \mathrm{~d}$. The linear regression coefficient $=1,340$ cells $/ \mu \mathrm{l}$ pr. doubling of Tl, $95 \% \mathrm{Cl} 831-1,849, P<0.001, n=112$.

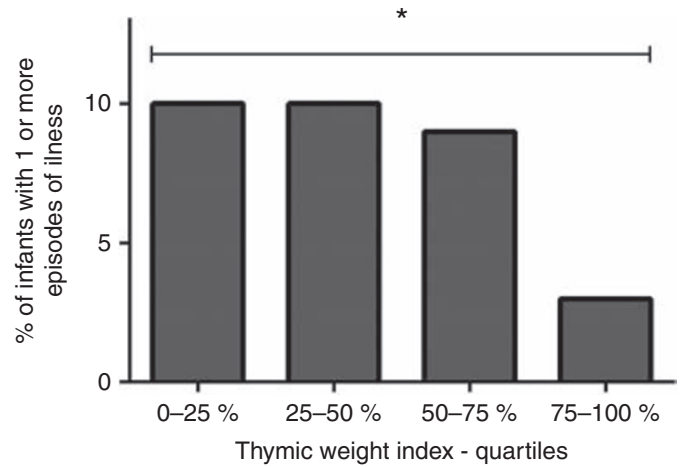

Figure 4. The association between thymic weight index at birth and subsequent infections in term infants. Infants are grouped into categories with none or at least 1 episodes of parent reported infections in the first 3 mo of life. Thymic size is given as quartiles of thymic weight index at birth. Compared with children in the three lower quartiles of TI, the children in the highest quartile had a $75 \%$ decrease in risk of infections, $P=0.05$.

BCG is due to modulations of the innate immune response this could explain our finding of no effect on thymic size.

We found significant positive associations between the absolute count of $\mathrm{CD} 4^{+}$RTEs, $\mathrm{CD} 8^{+}$RTEs $\mathrm{CD} 4^{+} \mathrm{T}$ cells, $\mathrm{CD} 8^{+} \mathrm{T}$ cells, lymphocytes, and thymic size in the newborn. This was strongest for lymphocytes, and stronger for the weightadjusted TWI compared to TI, indicating that a doubling in TWI increases the amount of circulating lymphocytes by 1,498 cells $/ \mu$ l. This links neonatal thymic size to immune function. To our knowledge this is the first time an association between specific thymic output measured as RTEs and TI/TW has been shown. An association between proportions of CD8+ T cells but not CD4+ T cells and TI at 10 mo of age has earlier been shown (20), others found no correlation between proportions of CD4+ and CD8+ T cells and TI $(21,22)$. RTEs constitute an early population of $\mathrm{T}$ cells recently generated in the thymus and exported into the peripheral blood. Recently, it was reported that measuring CD4+ RTEs by flow cytometry, using CD31 as a surface biomarker as in our study, is as valid as measuring $\mathrm{T}$ cell receptor excision circles (TRECs) with regard to evaluating thymic output (23). Our findings suggest that the used ultrasonic assessment of TI/TWI may be useful in evaluating neonatal thymic output. A method which is noninvasive, considered safe (18), shown to be reproducible and correlate with autopsy findings of actual thymic volume (16). However, we are not able to conclude on the causality between thymic size, lymphocytes and risk of infection; hence it is possible that thymic size, $\mathrm{T}$ cells subsets and peripheral lymphocytes are all "barometers of good health," but do not play a causal role in infants having fewer infections.

None of the infants in the present study were premature, low for gestational age, lymphopenic, or showed signs or symptoms of immunodeficiency. If the association between function and size of the thymus is similar in immunologically challenged 
infants, a small thymus at birth may result in a low peripheral $\mathrm{T}$ cell pool and a narrow $\mathrm{T}$ cell repertoire. This could provide a potential biological mechanism behind the findings of mortality being inversely related to thymic size $(12,24)$. Several factors are known to affect thymic size, both in a thymopoietic (e.g., weight, gestational age, breastfeeding) and a thymolytic (e.g., infection, physiological stress, glucocorticoids and age) manner (25). The influence by several different factors on thymic size might explain why the association between output and size becomes nonsignificant at age 3 mo.

Our results of reduced risk of infections in the first 3 mo of life with increasing thymic size at birth support findings of an association between infectious disease and thymic size. Previous studies have mainly shown that infections in a high income country lead to a smaller thymic size (26), but in this study we show that a larger thymic size at birth leads to fewer infections. This finding corroborates findings from West Africa, where a large thymic size was associated with reduced mortality $(12,13)$. To our knowledge, this is the first time thymic size has been shown to potentially predict subsequent health measured as reduced number of infections in a high income country.

In conclusion, BCG vaccination at birth does not affect thymic size at 3 mo of age measured as thymic index and thymic/ weight index in healthy term infants. Overall, the study supported that thymic size may be a marker of subsequent health due to less infectious disease, and demonstrated, for the first time, a positive association between thymic size and RTEs. Ultrasound to assess TI and TWI may be a useful way to identify immunologically vulnerable neonates in low income settings where flow cytometry is not an option.

\section{ACKNOWLEDGMENTS}

The authors gratefully acknowledge the participation of the children and their parents. The authors also thank Birgit Peitersen and Monica Ladekarl for invaluable assistance.

\section{AUTHOR CONTRIBUTIONS}

C.B., D.L.J., O.P., T.N.N., and N.M.B. conceived and designed the experiments. L.G.S., D.L.J., P.E.K., O.P., and S.D.N. supervised the collection of data. J.K. and L.M.T. participated in the overall data collection. N.M.B. and V.Z. performed the ultrasound examinations. N.M.B. and T.N.N. organized and managed the thymus cohort. N.M.B. carried out data management and analyzed the data. A.A. supervised the statistical analyses. N.M.B. drafted the manuscript. All authors read and approved the final manuscript.

\section{STATEMENT OF FINANCIAL SUPPORT}

The study was funded by Copenhagen University Hospital, Hvidovre, the Danish National Research Foundation (DNRF108), and the Dagmar Marshall Foundation. The scanner used was funded by the Novo Nordisk foundation. The funders had no role in the study design, data collection and interpretation, or decision to submit the work for publication. We have no competing interests, financial or otherwise.

Disclosure: L.G.S. received grants from Danish National Research Foundation during the conduct of the study. S.D.N. reports grants from the Dagmar Marshalls Foundation, the Novo Nordisk Foundation and travelling grants from Gilead, BMS, MSD, and ViiV/GSK during the conduct of the study. The funders had no role in the study design, data collection and interpretation, or decision to submit the work for publication. We have no competing interests, financial or otherwise.

\section{REFERENCES}

1. Garly M-L, Martins CL, Balé C, et al. BCG scar and positive tuberculin reaction associated with reduced child mortality in West Africa. Vaccine 2003;21:2782-90.

2. Roth A, Gustafson P, Nhaga A, et al. BCG vaccination scar associated with better childhood survival in Guinea-Bissau. Int J Epidemiol 2005;34: 540-7.

3. Roth A, Sodemann M, Jensen H, et al. Tuberculin reaction, BCG scar, and lower female mortality. Epidemiology 2006;17:562-8.

4. Aaby P, Roth A, Ravn H, et al. Randomized trial of BCG vaccination at birth to low-birth-weight children: beneficial nonspecific effects in the neonatal period? J Infect Dis 2011;204:245-52.

5. Biering-Sørensen S, Aaby P, Napirna BM, et al. Small randomized trial among low-birth-weight children receiving bacillus Calmette-Guérin vaccination at first health center contact. Pediatr Infect Dis J 2012;31: 306-8.

6. Rieckmann A, Villumsen M, Sørup S, et al. Vaccinations against smallpox and tuberculosis are associated with better long-term survival: a Danish case-cohort study 1971-2010. Int J Epidemiol 2016;0:1-11

7. Benn CS, Netea MG, Selin LK, Aaby P. A small jab - a big effect: nonspecific immunomodulation by vaccines. Trends Immunol 2013;34:431-9.

8. Kleinnijenhuis J, Quintin J, Preijers F, et al. Bacille Calmette-Guerin induces NOD2-dependent nonspecific protection from reinfection via epigenetic reprogramming of monocytes. Proc Natl Acad Sci USA 2012;109:17537-42.

9. Djuardi Y, Sartono E, Wibowo H, Supali T, Yazdanbakhsh M. A longitudinal study of BCG vaccination in early childhood: the development of innate and adaptive immune responses. PLoS One 2010;5:e14066.

10. Marchant A, Goetghebuer T, Ota MO, et al. Newborns develop a Th1-type immune response to Mycobacterium bovis bacillus Calmette-Guérin vaccination. J Immunol 1999;163:2249-55.

11. Domínguez-Gerpe L, Rey-Méndez M. Evolution of the thymus size in response to physiological and random events throughout life. Microsc Res Tech 2003;62:464-76.

12. Aaby P, Marx C, Trautner S, et al. Thymus size at birth is associated with infant mortality: a community study from Guinea-Bissau. Acta Paediatr 2002;91:698-703.

13. Garly ML, Trautner SL, Marx C, et al. Thymus size at 6 months of age and subsequent child mortality. J Pediatr 2008;153:683-8, 688.e1-3.

14. Thøstesen LM, Nissen TN, Kjærgaard J, et al. Bacillus Calmette-Guérin immunisation at birth and morbidity among Danish children: A prospective, randomised, clinical trial. Contemp Clin Trials 2015;42: 213-8.

15. Kjærgaard J, Birk NM, Nissen TN, et al. Nonspecific effect of BCG vaccination at birth on early childhood infections: a randomized, clinical multicenter trial. Pediatr Res 2016;80:681-5.

16. Hasselbalch H, Nielsen MB, Jeppesen D, Pedersen JF, Karkov J. Sonographic measurement of the thymus in infants. Eur Radiol 1996;6:700-3.

17. Stensballe LG, Nante E, Jensen IP, et al. Acute lower respiratory tract infections and respiratory syncytial virus in infants in Guinea-Bissau: a beneficial effect of BCG vaccination for girls community based case-control study. Vaccine 2005;23:1251-7.

18. Shankar H, Pagel PS. Potential adverse ultrasound-related biological effects: a critical review. Anesthesiology 2011;115:1109-24.

19. Wilson ME, Fineberg HV, Colditz GA. Geographic latitude and the efficacy of bacillus Calmette-Guérin vaccine. Clin Infect Dis 1995;20:982-91.

20. Jeppesen DL, Hasselbalch H, Lisse IM, Ersbøll AK, Engelmann MD. T-lymphocyte subsets, thymic size and breastfeeding in infancy. Pediatr Allergy Immunol 2004;15:127-32.

21. Hasselbalch H, Jeppesen DL, Ersbøll AK, Lisse IM, Nielsen MB. Sonographic measurement of thymic size in healthy neonates. Relation to clinical variables. Acta Radiol 1997;38:95-8.

22. Nassar MF, Younis NT, Tohamy AG, Dalam DM, El Badawy MA. T-lymphocyte subsets and thymic size in malnourished infants in Egypt: a hospital-based study. East Mediterr Health J 2007;13:1031-42. 


\section{Articles | Birketal.}

23. Ravkov E, Slev P, Heikal N. Thymic output: assessment of CD4+ recent thymic emigrants and T-cell receptor excision circles in infants. Cytom Part B 2016;00B:0-0.

24. Moore SE, Fulford AJ, Wagatsuma Y, Persson LÅ, Arifeen SE, Prentice AM. Thymus development and infant and child mortality in rural Bangladesh. Int J Epidemiol 2014;43:216-23.

25. Dooley J, Liston A. Molecular control over thymic involution: from cytokines and microRNA to aging and adipose tissue. Eur J Immunol 2012;42: 1073-9.

26. Jeppesen DL, Ersbøll AK, Nielsen SD, Hoppe TU, Valerius NH. Low thymic size in preterm infants in the neonatal intensive care unit, a possible marker of infection? A prospective study from birth to 1 year of age. Acta Paediatr 2011;100:1319-25.
This work is licensed under a Creative Commons

Attribution-NonCommercial-NoDerivs $\quad \mathbf{4 . 0}$ International License. The images or other third party material in this article are included in the article's Creative Commons license, unless indicated otherwise in the credit line; if the material is not included under the Creative Commons license, users will need to obtain permission from the license holder to reproduce the material. To view a copy of this license, visit http://creativecommons.org/licenses/ by-nc-nd/4.0/

(C) The Author(s) (2017) 